\title{
Mobilidade Urbana e Redução de Acidentes de Trânsito
}

Valdionor Alves da Cruz Filho $^{1}$; Deise Cristiane Nascimento ${ }^{2}$

Resumo: Este artigo tem a finalidade de compreender como a mobilidade urbana impacta na redução de acidentes de transito. $\mathrm{O}$ estudo se deu a partir da análise de casos de mobilidade urbana exitosas em outros municípios do Brasil e de outros países. Aponta também a necessidade da gestão de políticas públicas a partir das especificidades do município de Juazeiro/BA, prevendo a redução do número de acidentes por meio de ferramentas de informação e colaboração através do poder público e sociedade civil, prevendo alternativas de planejamento, concepção e execução na gestão pública para a mobilidade urbana.

Palavras-chave: mobilidade urbana, redução de acidentes de trânsito, qualidade de vida.

\section{Urban Mobility and Traffic Accident Reduction}

\begin{abstract}
This article aims to understand how urban mobility impact on reducing traffic accidents. The study was performed based on the analysis of cases of successful urban mobility in other municipalities in Brazil and other countries. It also points to the need for management of public policies from the specifics of the city of Juazeiro / BA, providing for the reduction of accidents through information and collaboration tools through the government and civil society, providing planning options, design and implementation in public administration for urban mobility.
\end{abstract}

Keywords: urban mobility, reduce traffic accidents, quality of life .

\section{Introdução}

As necessidades sociais e econômicas das pessoas requerem seu deslocamento no espaço, que pode ser feito a pé ou por meio de veículos de transporte motorizados ou não motorizados. Em economias em desenvolvimento, como o Brasil, as pessoas que moram nas cidades realizam, em média, dois deslocamentos por dia (média entre as que se deslocam e as que não se deslocam), valor correspondente à metade dos deslocamentos de pessoas em países desenvolvidos (VASCONCELLOS, 2002). Assim, em cidades grandes do Brasil com população de 3 milhões de pessoas são realizados por dia 6 milhões de deslocamentos.

\footnotetext{
1 Administração. Universidade Federal do vale do São Francisco - UNIVASF. raduado em Geografia, Mestre em Desenvolvimento Regional, Doutor em Geografia pela UNESP, Rio Claro. Professor do quadro permanente do Instituto Federal de Educação, Ciência e Tecnologia do Ceará, campus Juazeiro do Norte. E-mail: valdircruz45@gmail.com;

${ }^{2}$ graduação em Ciências Econômicas pela Universidade Federal de Santa Maria (2001). Atualmente é professor auxiliar da Faculdade de Ciências Aplicadas e Sociais de Petrolina.
} 
Id on Line Revista Multidisciplinar e de Psicoloqia

Id on Line Revista Multidisciplinar e de Psicologia

Esses deslocamentos são feitos com maior ou menor nível de conforto, conforme as condições específicas em que se realizam e implicam consumos de tempo, espaço, energia e recursos financeiros e geração de externalidades negativas, como a poluição do ar, os acidentes de trânsito e os congestionamentos.

Em razão do intenso crescimento urbano no Brasil, a partir da década de 1960, muitas cidades - e regiões metropolitanas - passaram a apresentar sistemas de mobilidade de baixa qualidade e de alto custo, com impactos negativos na vida das pessoas e nos custos econômicos e ambientais para a sociedade. Assim, o estudo das condições efetivas de mobilidade (por extrato social), dos consumos e das externalidades a elas associadas, é fundamental para avaliar a qualidade da vida urbana no país e para identificar ações de políticas públicas que possam reduzir os problemas e melhorar a qualidade geral de vida e a eficiência da movimentação de pessoas e mercadorias.

Já em cidades de menor porte estão aumentando progressivamente esses deslocamentos e isso reflete numa queda da mobilidade urbana. De acordo com Waisman (2000), um transporte público caro e de má qualidade gera um processo de exclusão social, cujo reflexo recai sobre a lentidão das cidades deixando-as menos interessantes para investimentos por causa da redução progressiva da mobilidade.

Nos últimos anos a região de juazeiro percebeu uma aceleração no crescimento da população, principalmente nos últimos 10 anos, acima da média nacional o que consequentemente fez com que mais pessoas buscando se locomover para o trabalho, negócios e lazer utilizassem como principal meio de locomoção o veículo, a consequência é que mais veículos nas ruas, gerou um grande problema que é a falta de espaço para tantos veículos, vagas nas vias públicas passou a ser tratado como o pote de ouro no final do arco-íris, mas há algo mais grave nesta nova demanda da sociedade. É que com essa maior quantidade de veículos percebemos que os acidentes envolvendo pedestres, ou seja, o atropelamento se tornou uma das causas que mais matam ou deixam sequelas como invalidez permanente ou temporária.

Então criou-se um dilema: Como resolver este problema de forma viável e que realmente se torne uma situação concreta e não paliativa? Abordaremos a discussão pautada em aspectos legais e de gestão pública através de indicadores como em conjunto com requisitos essenciais para pensar em alternativas como a saúde, mobilidade, sustentabilidade, educação, engenharia, planejamento e fiscalização na redução de acidentes de trânsito.

\section{Metodologia}

A metodologia baseada para o desenvolvimento das ações, efetivou-se através de análise 
Id on Line Revista Multidisciplinar e de Psicologia

Id on Line Revista Multidisciplinar e de Psicologia

quali-quantitativa, observando ferramentas públicas de controle e de pesquisas como as disponibilizadas pelo Instituto de Pesquisa Econômica Aplicada - IPEA e pelo Departamento Nacional de Transito - Denatran, prevendo buscar meios de redução do número de acidentes no trânsito. A devida pesquisa propôs verificar através da análise documental, como identificar melhorias de qualidade de vida dos habitantes dos locais pesquisados e, a partir disso, apontar perspectivas para a realidade local.

\section{Mobilidade urbana: saúde e sustentabilidade}

Para Oliveira (2010) sob o ponto de vista da saúde, o constante aumento dos índices de doenças e agravos não transmissíveis aponta para a necessidade de encarar estas questões também a partir do âmbito da saúde pública, tanto no que reporta à necessidade de melhorar os índices de atividade física dos brasileiros (e diminuir, assim, as taxas de morte por doenças não transmissíveis) quanto no que diz respeito à morbimortalidade por acidentes e violências, pois os acidentes de trânsito no Brasil são responsáveis por grande número de óbitos e pelo comprometimento orçamentário

Por outro lado, os orçamentos - públicos e privados - destinados à saúde são comprometidos pelos resultados desastrosos dos problemas urbanos, o que requer uma mudança de enfoque e uma inversão nas prioridades, implicando numa outra lógica de planejamento urbano, orientado para a prevenção e para a melhoria da qualidade de vida.

O modo de vida das populações é afetado pela organização do sítio urbano, e este fato nem sempre é considerado no planejamento das cidades. Algumas características da organização e do layout das cidades influenciam tanto as práticas diárias de deslocamento das pessoas (com ou sem veículos motorizados) quanto seus níveis de sedentarismo.

Na proposta de uma mudança de paradigma de planejamento urbano e ambiental, é preciso uma inversão na lógica das hierarquias, de maneira que a qualidade de vida, a natureza e o futuro sejam colocados no alto da escala de valores. Se houver uma maior conscientização comunitária e governamental sobre seus benefícios e a atividade física tornar-se uma prática socialmente valorizada, espera-se uma adesão maior das pessoas às práticas de deslocamento físico não motorizado, o que contribuirá para a melhoria da saúde das populações urbanas e para a inversão na lógica dos orçamentos públicos. O que se busca, atualmente, é a associação desta temática às questões mais amplas de planejamento urbano ligadas ao transporte. 
Id on Line Revista Multidisciplinar e de Psicologia

Id on Line Revista Multidisciplinar e de Psicologia

\section{Estratégias de planejamento e gestão para mobilidade urbana}

As cidades têm como papel principal maximizar a troca de bens e serviços, cultura e conhecimentos entre seus habitantes, mas isso só é possível se houver condições de mobilidade adequadas para os seus cidadãos. Neste sentido, a mobilidade é um atributo associado à cidade, e corresponde à facilidade de deslocamento de pessoas e bens na área urbana. A mobilidade traduz as relações dos indivíduos com o espaço em que habitam, com os objetivos e meios empregados para seu deslocamento e com os demais indivíduos que integram a sociedade (Ministério das Cidades, 2006).

Segundo Campos (2006) a preocupação com o desenvolvimento tem incentivado o estudo e a implantação, em diferentes setores de medidas, e procedimentos que contribuam para a sustentabilidade em áreas urbanas. Em relação aos transportes esta questão pode ser vista através de uma busca pela mobilidade urbana sustentável. Esta busca deve ter como base o conceito de desenvolvimento sustentável em que se procura de uma forma geral, definir estratégias dentro de uma visão conjunta de questões sociais, econômicas e ambientais. Além disso, deve-se ter como pensamento, o princípio mais exemplificado do desenvolvimento sustentável como "uma forma de desenvolvimento que vai ao encontro das necessidades da geração atual sem comprometer a possibilidade (ou capacidade) das gerações futuras em satisfazes as suas necessidades (PLUME, 2003).

Embora vaga, a palavra "sustentabilidade" tem sempre a pretensão de considerar simultaneamente os impactos das atividades humanas na perspectiva ambiental, de coesão social e de desenvolvimento econômico, tanto para atual quanto para as futuras gerações. A avaliação de impactos é cada vez mais necessária em todos os campos de intervenções políticas para decidir sobre a utilização otimizada de recursos limitados de que se dispõe, a fim de intensificar a competitividade econômica, melhorar o ambiente, aumentar a coesão social nas cidades e aumentar a qualidade de vida da população. Neste sentido, a mobilidade sustentável é uma questão-chave. Assim, os métodos e práticas para atingi-la devem ser delineados, experimentados e divulgados para abrir caminhos e melhorias na qualidade dos transportes e de vida urbana (TRANSPLUS, 2002).

Conforme Costa (2008) a multiplicidade de definições se reflete também nas diferentes denominações que o conceito de transporte sustentável tem recebido ao redor do mundo e inclusive no Brasil, refletindo preocupações e interesses específicos das comunidades interessadas em desenvolvelo. Entre as diferentes denominações encontradas estão: mobilidade sustentável, transporte ambientalmente sustentável, transporte urbano limpo, transporte humano, mobilidade cidadã, mobilidade para todos, entre outros. (Ministério das Cidades, 2006a).

No Brasil, a difusão do conceito de mobilidade sustentável tem sido coordenada pelo Ministério das Cidades, através da Secretaria Nacional de Transportes e da Mobilidade Urbana. Conforme a referida Secretaria, mobilidade sustentável é o conjunto de políticas de transporte e 
Id on Line Revista Multidisciplinar e de Psicologia

Id on Line Revista Multidisciplinar e de Psicologia

circulação que visa proporcionar o acesso amplo e democrático ao espaço urbano, através da priorização dos modos de transporte coletivo e não-motorizados de maneira efetiva, socialmente inclusiva e ecologicamente sustentável (ANTP, 2003b; Ministério das Cidades, 2006a SEMOB, 2008).

Ao mesmo tempo que emergem diferentes definições para mobilidade sustentável, inúmeros aspecto tem sido destacado nas iniciativas em se promover o conceito. Algumas questões incorporadas na definição de transporte sustentável dizem respeito a: (i) Maior integração entre as questões econômicas e ambientais na tomada de decisão e a necessidade

de maior participação e engajamento dos cidadãos nos processos políticos; (ii) Mudanças para novas tecnologias e energias alternativas; (iii) Otimização da logística dos fluxos de transporte; (iii) Mitigação dos congestionamentos urbanos, poluição de ar e ruídos; (vi) Conservação de recursos e eficiência econômica dos transportes (Gudmundsson, 2004).

Os diversos enfoques no tratamento das questões de mobilidade urbana, somado as especificidades locais, têm resultado no desenvolvimento de iniciativas, estudos e ferramentas para análise e desenvolvimento de ações para a mobilidade com características distintas ao redor do mundo. Considerações sobre algumas das principais iniciativas para a Mobilidade Urbana e sustentável em desenvolvimento são apresentadas a seguir.

\section{Iniciativas para a mobilidade urbana sustentável}

Iniciativas para promover o conceito de transporte sustentável já são bastante comuns em países desenvolvidos, e começam a emergir em países em desenvolvimento, como é o caso do Brasil. Estas iniciativas são observadas tanto no meio acadêmico, com destaque a estudos, pesquisas, ferramentas de análise, sistemas de indicadores, entre outros, como no meio técnico e profissional, e mais recentemente nas esferas política e administrativa. Neste último caso, merecem destaque políticas nacionais de transporte sustentável e estratégias no nível das cidades, observadas especialmente em países da Europa.

Alguns países da Europa e da América do Norte são pioneiros na pesquisa de um novo conceito de mobilidade e no desenvolvimento e aplicação de indicadores para a monitoração das políticas e estratégias implementadas. Na Europa, o foco principal das medidas desenvolvidas está sobre a integração das questões ambientais nas demais políticas públicas. Nos Estados Unidos, sistemas de indicadores são desenvolvidos em todos os níveis, formalizando os planos e programas e mantendo forte ligação com os objetivos estabelecidos pelo governo. No Canadá, ferramentas para medir a performance de políticas públicas também incluem relatórios sobre desenvolvimento sustentável baseados na observação de indicadores, combinando elementos e estruturas presentes nas experiências da Europa e Estados Unidos (Gudmundsson, 2001). 
Id on Line Revista Multidisciplinar e de Psicoloqia

Id on Line Revista Multidisciplinar e de Psicologia

Na Europa há ainda uma extensa pesquisa sobre questões de desenvolvimento, planejamento de transportes e uso do solo, tais como TRANSPLUS, ECOCITY, entre outros.

No caso do Brasil, o movimento em direção a mobilidade urbana sustentável tem seus primeiros esforços empreendidos pelo Governo Federal. Entre outras iniciativas, merece destaque o programa de treinamento para técnicos e planejadores em nível municipal em que o principal objetivo foi trabalhar um novo conceito de mobilidade inteiramente adaptado à realidade dos municípios onde o curso foi realizado (Silva et al., 2007). Somam-se a esta iniciativa programas como:

- A Plataforma Catarinense de Mobilidade Sustentável, que consiste em um programa do Governo do Estado de Santa Catarina, que conta com a participação das municipalidades, universidades e da sociedade civil organizada, para incentivar e dar suporte ao desenvolvimento de políticas de transporte sustentáveis em cidades catarinenses (DEINFRA, 2008);

- O Projeto MOVIMAN Porto Alegre, financiado pela União Européia e pelo município de Porto Alegre e desenvolvido entre os meses de junho de 2005 a setembro de 2006. O objetivo principal do projeto foi a busca por novas formas de cooperação entre administração pública, empresas locais, empresas de transporte e usuários, com o objetivo de alcançar satisfação eficiente, econômica e ecológica de todas as necessidades inerentes à mobilidade (EPTC, 2006).

A grande quantidade de iniciativas desenvolvidas limita uma análise pormenorizada das mesmas, mesmo que focalizando aquelas desenvolvidas somente nos últimos cinco anos. Deste modo, e de forma a proporcionar uma visão geral do que vem sendo empreendido em matéria de mobilidade sustentável, especialmente na Europa, a Tabela 1 apresenta uma relação de estudos, pesquisas e iniciativas de natureza diversa relacionadas ao tema.

Algumas destas iniciativas focam em aspectos específicos da mobilidade urbana, tais como: transporte não-motorizado, eficiência energética, novas tecnologias, impactos ambientais, estratégias de gerenciamento da demanda por transportes, entre outros. Abordam ainda questões de integração entre o planejamento de transportes e uso do solo.Muitas das iniciativas listadas na Tabela 1 de autoria de $\operatorname{Costa}^{4}$ (2008) contemplam sistemas de indicadores para monitoração de aspectos relacionados à sustentabilidade dos sistemas de transportes.

\footnotetext{
${ }^{4}$ Tese apresentada na Universidade de São Paulo para obtenção do grau de Doutor em Engenharia Civil. Área de concentração de transportes. Ano de obtenção: 2008. 
Id on Line Revista Multidisciplinar e de Psicologia

Id on Line Revista Multidisciplinar e de Psicologia

Tabela 1: Estudos e iniciativas sobre transporte e mobilidade sustentável.

\begin{tabular}{|c|c|c|}
\hline Estudo/lniciativa & Informações & Endereço na Intemet \\
\hline Eoocity & $\begin{array}{l}\text { Desenvolvimento urbano direcionado a estruturas adequadas para o } \\
\text { transporte sustentável. }\end{array}$ & $\begin{array}{l}\text { Disponivel em: http:fwww. ecoctvproiects.net: } \\
\text { Acesso em: } 21 \text { mai } 2016 .\end{array}$ \\
\hline Niches. & $\begin{array}{l}\text { Projeto que visa faciitar a coordenaçăo de atividades de pesquisa acadèmica } \\
\text { por parte de insfituiçóes, industria, operadores e autoridades de transporte na } \\
\text { área de conceitos incyadores de transcorte urhane. }\end{array}$ & $\begin{array}{l}\text { Disponivel em:www.niches-transporton } \\
\text { Acesso em: } 21 \mathrm{mai} .2016 \text {. }\end{array}$ \\
\hline Rilot & $\begin{array}{l}\text { Projeto europeu que apresenta a preparaç3̆o dos planos de transporte urbano } \\
\text { sustentavel das cldades de Bralia, Evora, Lancaster eTalinn. }\end{array}$ & $\begin{array}{l}\text { Disponivel em: http: / www. pilot-transportood } \\
\text { Acesso em: } 21 \text { mai. } 2016 \text {. }\end{array}$ \\
\hline $\begin{array}{l}\text { Sustainable Developmert } \\
\text { Gateway }\end{array}$ & $\begin{array}{l}\text { Portal do Instituto Internacional para o desenvolvimento sustentável com } \\
\text { estudos e projetos sobre transporte sustentável. }\end{array}$ & $\begin{array}{l}\text { Disponivel em: } \\
\text { http://www.sdgateway.nettogics/111.htm } \\
\text { Acesso em: } 21 \text { mai. } 2016 .\end{array}$ \\
\hline Sutra & $\begin{array}{c}\text { Tem por objetivo desenvolver uma abordagem e metodologia consistente } \\
\text { para análise dos problemas de transporte e auxiliar no desenvolvimento de } \\
\text { estratégias de desenvolvimento sustentável. }\end{array}$ & $\begin{array}{l}\text { Disponivel em: http: / www.es5.00.st/SUTRA } \\
\text { Acesso em: } 21 \text { mai. } 2016 .\end{array}$ \\
\hline Transplus & $\begin{array}{l}\text { Extensa relaçăo de fontes de dados e informaçòes sobre transportes en nivel } \\
\text { internacional, especialmente na Europa, Asia e América do Norte. } \\
\text { Tem por objetivo identificar boas práticas na organizaçăo dos transpones e } \\
\text { uso do solo visando reduzir a dependéncia do automóvel em cidades } \\
\text { suropaias. }\end{array}$ & $\begin{array}{l}\text { Disponivel em: http:llwuw. trans plus.nef } \\
\text { Acesso em: } 21 \text { mai. } 2016 .\end{array}$ \\
\hline World Business Council & $\begin{array}{l}\text { Publicapóes e estudos de caso do Conselho Mundial de Negócios } \\
\text { para o Desenvolvimento Sustertável sobre transportes emobilidade }\end{array}$ & $\begin{array}{l}\text { isponivel em: http:in psoenome-compass.pbwiki.com/ } \\
\text { vesso em: } 21 \text { mai. } 2016 \text {. }\end{array}$ \\
\hline
\end{tabular}

\section{Indicadores urbanos}

A partir deste espaço está inserida a metodologia deste trabalho, que procurou pautarse incisivamente pela análise de dados estatísticos através de ferramentas de gestão pública do setor de controle de mobilidade urbana e de trânsito que abordam a temática como o Instituto de Pesquisa e Economia Aplicada - IPEA, o Departamento Nacional de Trânsito DENATRAN em conjunto com o Observatório das Metrópoles e através de referências bibliográficas, bem como estudos de casos nacionais e internacionais.

Por tanto o resultado final dessa primeira análise do objeto de estudo é trazer perspectivas a luz do tema com o objetivo de produzir indicadores de mobilidade sustentável são tratados de forma detalhada neste capítulo, abordando suas características, aplicações e aspectos que devem ser considerados na construção de sistemas para monitoração da 
Id on Line Revista Multidisciplinar e de Psicoloqia

Id on Line Revista Multidisciplinar e de Psicologia

mobilidade urbana. Uma relação de indicadores propostos em trabalhos conduzidos em diversos países é apresentada neste capítulo. Em uma etapa final são feitas considerações a respeito dos indicadores de transportes e mobilidade em desenvolvimento no Brasil.

Por essa razão, menos automóveis nas ruas e menos trânsito também implicam em uma melhoria de bem-estar geral, desde que haja provisão adequada de transporte público. Perder tempo em deslocamentos costuma ser negativo para as utilidades individuais. Caso esse tempo diminua, a utilidade geral aumenta. A redução do stress contribui da mesma forma para melhoria na qualidade de vida. Os transportes individuais também são responsáveis por uma grande quantidade de acidentes, provocando mortes ou graves danos à saúde para milhares de indivíduos por ano, principalmente jovens (de 18 a 25 anos), como pode ser visto no Gráfico 1, abaixo:

\section{Gráfico 1. Evolução dos óbitos por acidentes de transporte (por mil). População} Total e Jovem do Brasil, 1994/2008.

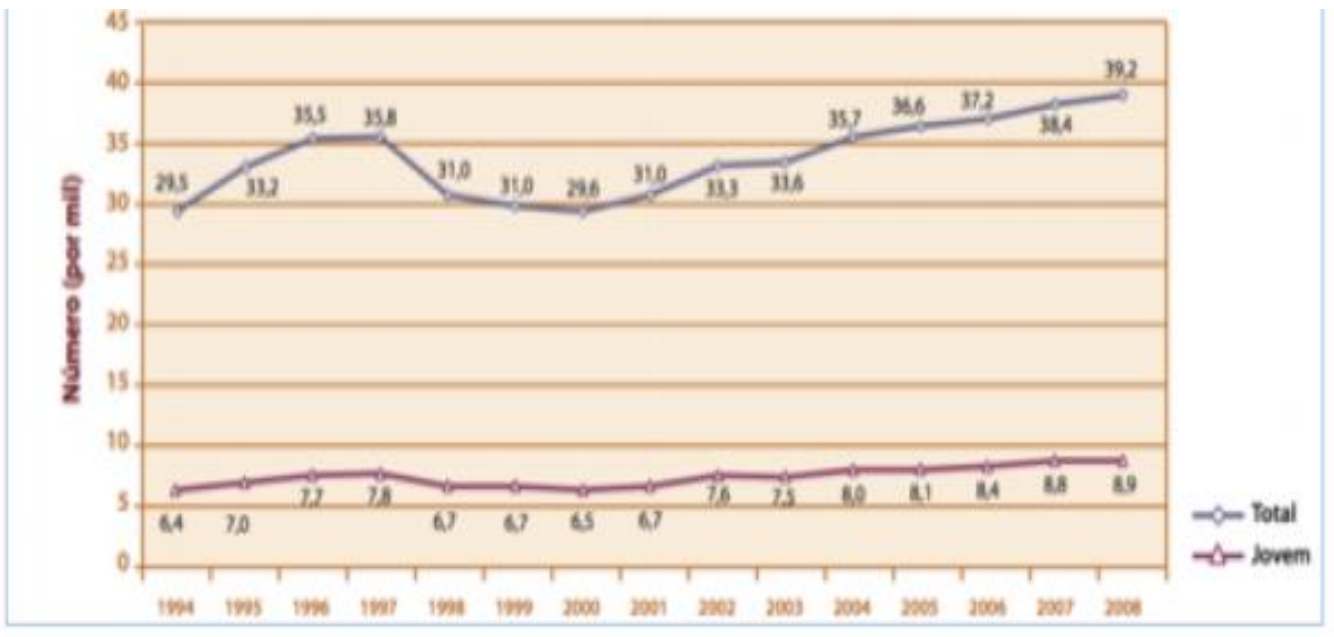

Fonte: WAISELFISZ, 2011

O gráfico 1 mostra que mais de 30 mil vidas por ano são perdidas em função de acidentes de trânsito (sendo mais de um quinto representado por jovens), e esses números vêm crescendo anualmente. Em estudo do IPEA, o custo dos acidentes de trânsito em aglomerados urbanos foi avaliado em 10,5 bilhões em 2011. (WAISELFISZ,2013).

Outro fator que pode contribuir com o desenvolvimento do transporte de forma geral para o Brasil em comparação com países europeus como Inglaterra e França são evidentes: Naqueles países, estruturas ferroviárias e metroviárias são mais eficientes, permitindo um melhor funcionamento dos ônibus (devido a maior previsibilidade do trânsito), levando ao 
Id on Line Revista Multidisciplinar e de Psicologia

Id on Line Revista Multidisciplinar e de Psicologia

maior uso dos transportes públicos, inclusive em cidades pequenas. Evidentemente, os países em questão possuem uma quantidade maior de recursos disponíveis, mas também gastam uma parcela maior de seu PIB com gastos em transporte. Podemos verificar os diversos incentivos dos países europeus a utilização do transporte público no gráfico 2 elaborado pelo IPEA $^{5}$.

\section{Gráfico 2. Distribuição da Receita dos Transportes de Massa nas Principais Cidades da} Europa, 2012.

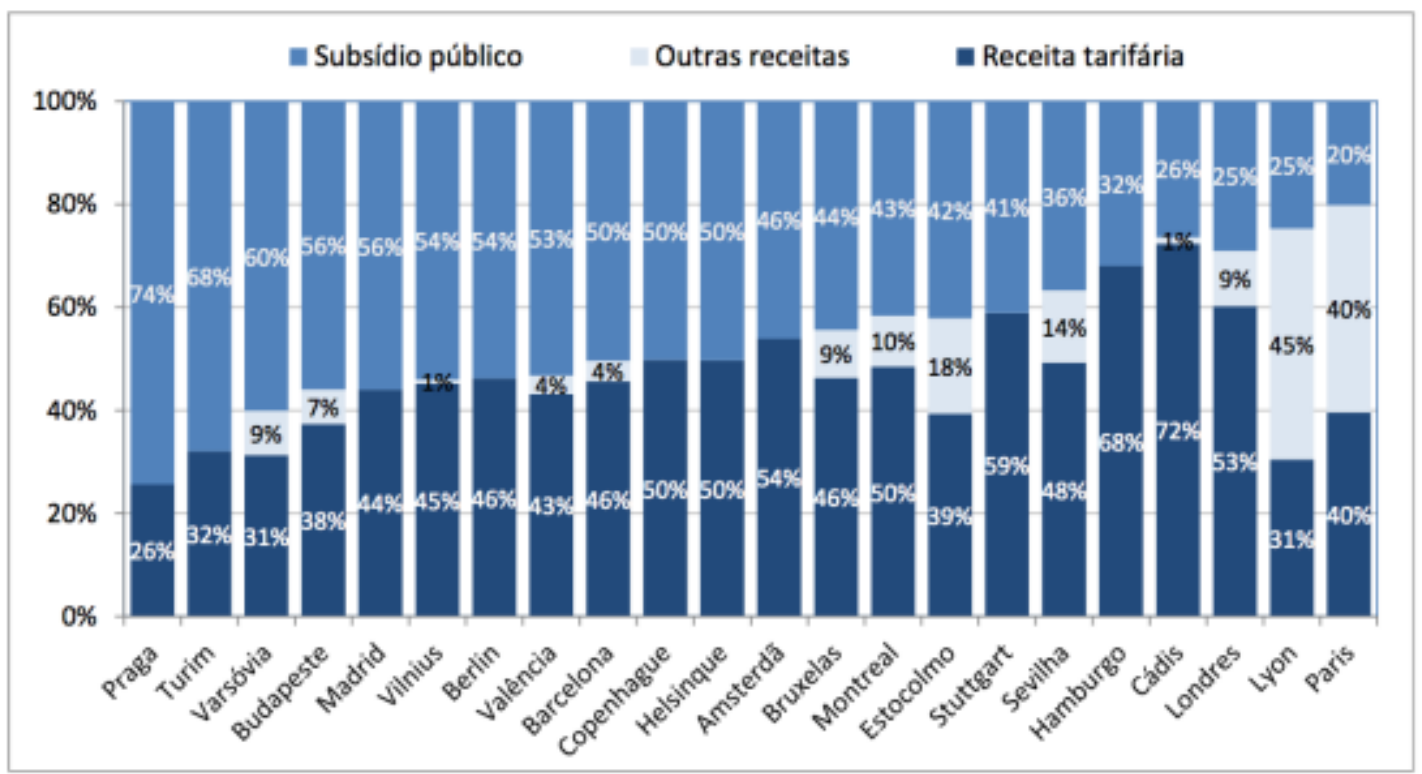

Fonte: IPEA, 2013.

Em estudo recente feito por uma empresa especializada em serviços de GPS (TomTom 2013), Rio de Janeiro e São Paulo foram incluídas entre as dez cidades com maiores congestionamentos no mundo, sendo as líderes absolutas no continente americano. Os cálculos foram realizados estimando a diferença de tempo para se realizar rotas nas principais vias de cada cidade em horários de pico e em horários de trânsito livre. Esse resultado confirma a percepção social de ineficiência na oferta de transportes no Brasil. Os resultados poderiam ser ainda mais alarmantes caso outras cidades brasileiras estivessem classificadas, além de Rio de Janeiro e São Paulo.

\footnotetext{
${ }^{5}$ Instituto de Pesquisa e Economia Aplicada. 
Id on Line Revista Multidisciplinar e de Psicoloqia

Id on Line Revista Multidisciplinar e de Psicologia

Gráfico 3. Cidades com maior transito no continente Americano

\begin{tabular}{|c|c|c|c|c|c|c|c|c|}
\hline \multicolumn{9}{|c|}{ Top 10 cities } \\
\hline Rank & Clchange & City & Country & Congestion & Morning peak & Evening peak & Hghways & Non-Highways \\
\hline 1 & A & Foo de Janeiro & Brazil & $50 \%$ & $96 \%$ & $125 \%$ & $44 \%$ & $53 \%$ \\
\hline 2 & 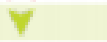 & 550 Paulo & Brazil & $39 \%$ & $66 \%$ & $100 \%$ & $30 \%$ & $47 \%$ \\
\hline 3 & A & Vancouver & Canada & $36 \%$ & $61 \%$ & $76 \%$ & $23 \%$ & $40 \%$ \\
\hline 4 & $\hat{A}$ & Los Angeles & United States & $35 \%$ & $55 \%$ & $78 \%$ & $33 \%$ & 385 \\
\hline 5 & $\hat{A}$ & San Francisco & United States & $32 \%$ & $53 \%$ & $71 \%$ & $28 \%$ & $37 \%$ \\
\hline 6 & $\nabla$ & Honolulu & United States & $28 \%$ & $36 \%$ & $59 \%$ & $19 \%$ & 364 \\
\hline 7 & A & Seattle & United States & $28 \%$ & $50 \%$ & $76 \%$ & $22 \%$ & $35 \%$ \\
\hline 8 & $\widehat{A}$ & San Jose & United States & $27 \%$ & $53 \%$ & $73 \%$ & $19 \%$ & 3840 \\
\hline 9 & $\ldots$ & Toronto & Canada & $27 \%$ & $54 \%$ & $72 \%$ & $21 \%$ & $34 \%$ \\
\hline 10 & A & Washington & United States & 278 & $49 \%$ & $66 \%$ & $20 \%$ & $34 \%$ \\
\hline
\end{tabular}

Fonte: TomTom ${ }^{6}, 2013$.

Como pode ser observado, o estado tem participação fundamental para a provisão de infraestrutura eficiente para transportes. Esses incentivos devem existir porque a facilidade nos deslocamentos gera externalidades positivas além das 24 possibilidades do mercado. Dessa maneira, investimentos em mobilidade também são importantes para a melhoria na oferta de serviços essenciais, como educação e saúde.

A partir de uma verificação ampla, tentaremos tipificar para a realidade especifica de análise e pensar como essas questões podem ser desenvolvidas na cidade de Juazeiro.

\section{Características atuais de mobilidade e aspectos locais de Juazeiro}

Juazeiro é um município brasileiro do estado da Bahia. Possui de acordo com o IBGE/2013 aproximadamente 218 mil habitantes. Em conjunto com o vizinho município de Petrolina, em Pernambuco, forma o maior aglomerado urbano do semiárido. Localizada na região sub-média da bacia do Rio São Francisco, a cidade se destaca pela agricultura irrigada que se firmou na região graças às águas do rio São Francisco.

As características atuais de mobilidade nas cidades do Brasil podem ser vistas pelos dados apresentados a seguir, baseados no Sistema de Informações da Mobilidade da Associação Nacional de Transportes Públicos (ANTP), referente aos municípios com mais de 60 mil habitantes, nos quais estão $70 \%$ da frota de veículos e $60 \%$ da população urbana do país.

${ }^{6}$ Empresa holandesa fabricante de sistemas de navegação para automóveis. 
Nos municípios com mais de 60 mil habitantes, existe um sistema viário de 282 mil quilômetros. A maioria dessas vias é do tipo local, que serve ao trafego dos moradores (77\%), havendo $11 \%$ de vias coletoras e $12 \%$ de vias artesanais e de transito rápido. A frota que circula nestes municípios é de 20 milhões de veículos, sendo 15,2 milhões de automóveis e veículos comerciais leves $(75,2 \%)$. A explicação para isso são as tendências gerais devido ao aumento das frotas de automóveis e de motociclistas. O gráfico 4 a seguir mostra a frota total de veículos automotores no Brasil elaborado pelo Observatório das Metrópoles a partir dos dados fornecidos pelo Departamento Nacional de Transito - DENATRAN.

Gráfico 4. Frota de veículos automotores no Brasil e por tipo de veículo - 2001 a 2012.

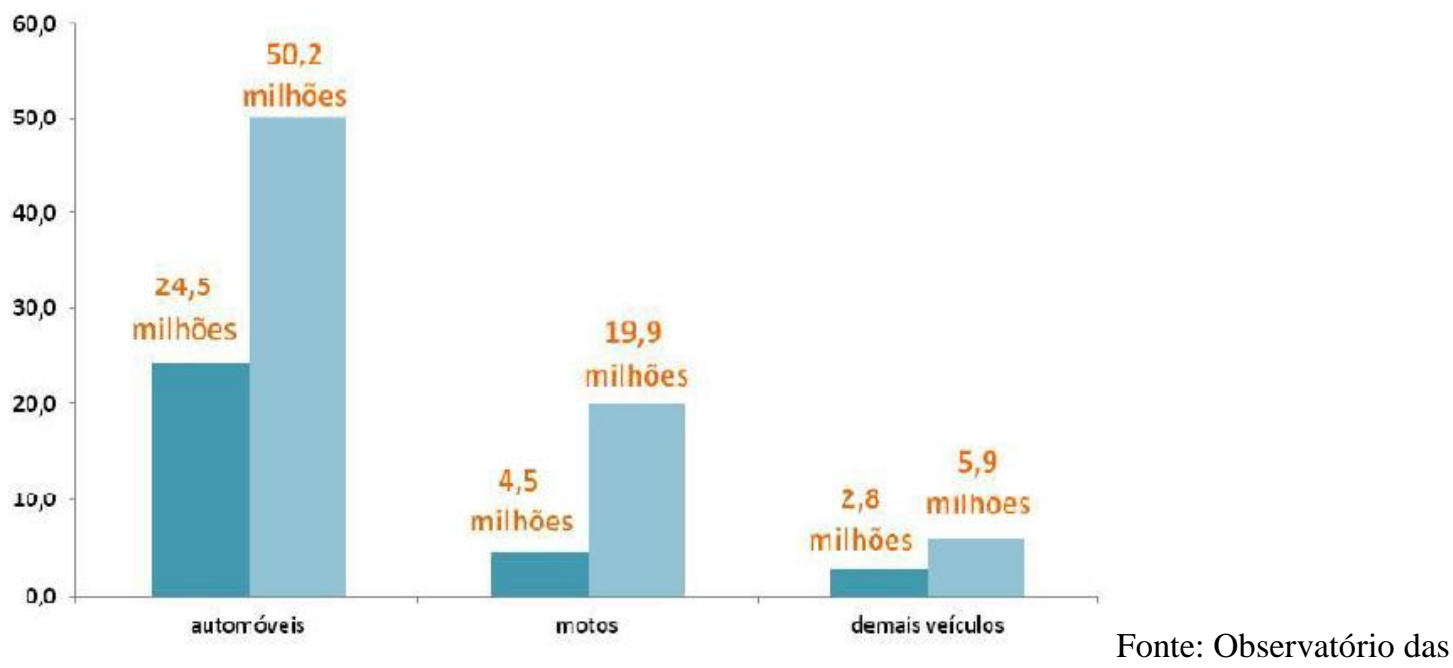

Metrópoles e DENATRAN.

Trazendo para a realidade local da pesquisa, vamos apresentar dados no gráfico 5 montantes ao crescimento da frota de automóveis no Brasil a partir do porte populacional de 2001 a 2012 em percentagem (\%). 


\section{Gráfico 5. Crescimento da frota de automóveis no Brasil a partir do porte populacional dos municípios - 2001 a 2012 (\%)}

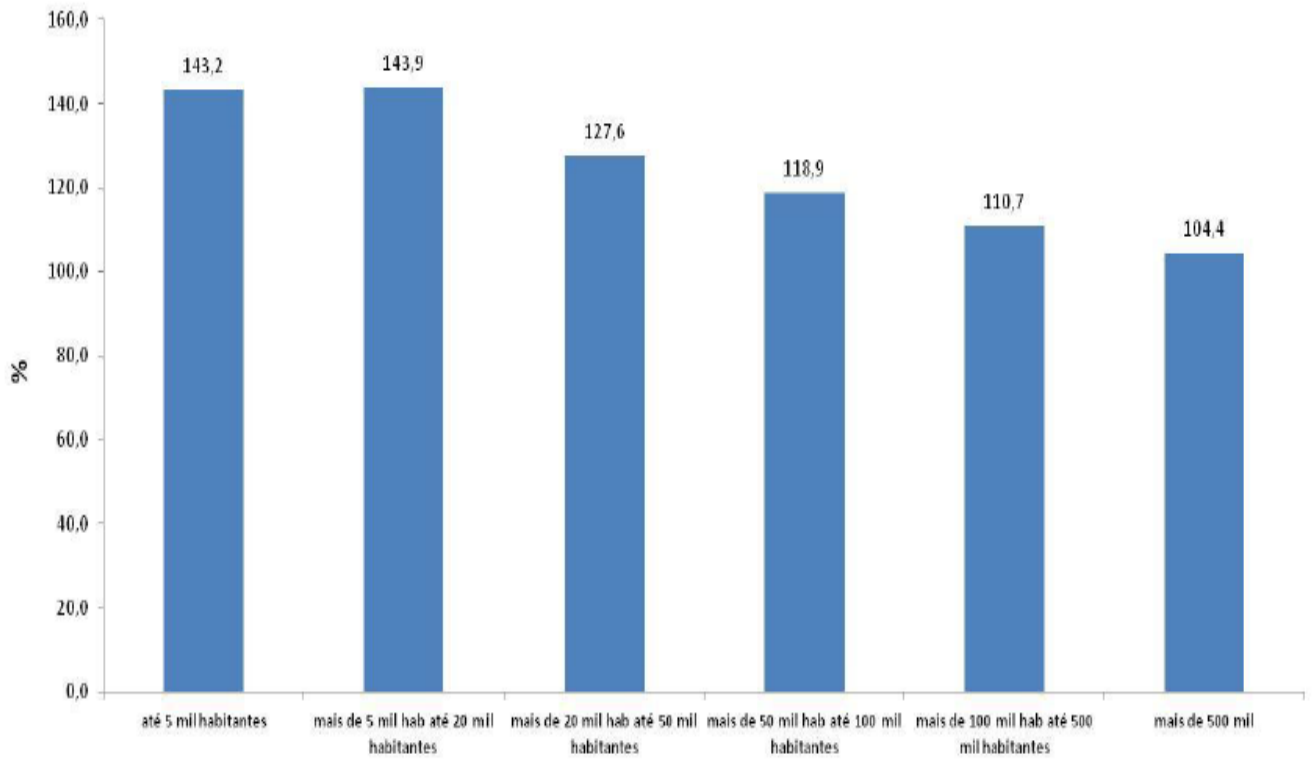

Fonte: Observatório das Metrópoles e DENATRAN.

A partir do gráfico, fica evidente que Juazeiro possa ser incluído na faixa de crescimento de $110,7 \%$ de crescimento de automóveis. O que mostra um grande aumento na proporção da frota de automóveis e com isso um lento deslocamento na região.

Cruzando os dados até então apresentados em consonância com a realidade local é necessário pensar nas demandas de mobilidade da cidade de Juazeiro e discutir de que forma novas ações podem ser previstas, elaboradas e executadas a partir da finalidade da pesquisa, verificaremos o grau de estrutura do município a partir da tabela 2 a seguir:

Tabela 2: Aspectos locais de mobilidade da cidade de Juazeiro/BA

Zona Azul

Dominação dada para áreas públicas em que o poder público local passa a cobrar pela utilização deste espaço. Juazeiro tem uma área bem limitada com poucas vagas a serem utilizado como parâmetro experiências de outras cidades em que conseguiram resolver estes problemas com a disponibilidade de mais vagas por outro lado aumentou suas receitas e tais recurso extras deverão ser investidos em melhorias dos espaços urbanos. 
Id on Line Revista Multidisciplinar e de Psicologia

Id on Line Revista Multidisciplinar e de Psicologia

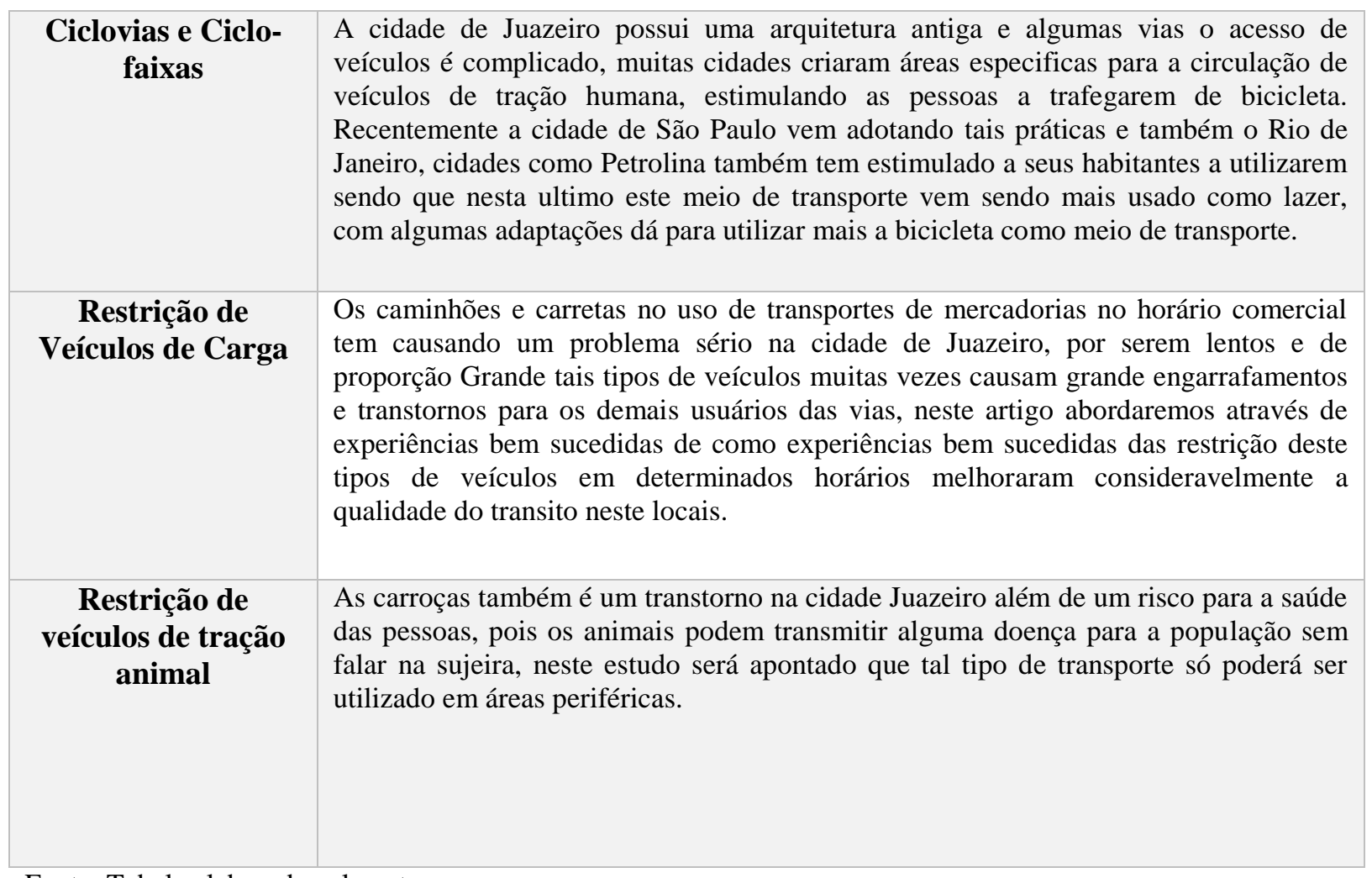

Fonte: Tabela elaborada pelo autor.

\section{Conclusão}

Pensar em questões de redução de mortalidade no transito e numa estruturação e modificação de mobilidade urbana a partir das modais apresentadas e com o crescente aumento de veículos automotores no transito, se faz a necessidade de pensar na aplicação da gestão do trânsito. A gestão da circulação é uma atividade essencial para a sustentabilidade das cidades e tem relação direta com a qualidade do transporte público e da circulação de seus usuários. Os maiores desafios estão resumidos a seguir. (i) prever recursos humanos e materiais: O maior desafio da operação de trânsito é dotar os municípios de recursos humanos e materiais adequados. Muitos municípios já dispõem de recursos, mas há grande quantidade de casos em que os recursos são limitados. (ii) informação técnica com qualidade: Uma forma de superar o problema é organizar processos de capacitação dos órgãos locais para obter dados, com apoio do Governo Federal na sugestão de normas gerais para o Brasil. O objetivo deve tornar disponível para a sociedade dados confiáveis, completos e atualizados, sobre acidentes de trânsito. (iii) insuficiência da fiscalização: A esse respeito, um dos desafios é o 
aumento da coordenação de esforços de fiscalização desses dois níveis de governo, principalmente por meio de convênios específicos.

Outro desafio é a organização completa e definitiva dos cadastros nacionais de condutores e de infrações. (iv) impunidade: Um dos maiores desafios a vencer é a reação de parte da sociedade à atuação dos agentes de fiscalização. Parte dessa reação está ligada à imagem negativa historicamente formada a respeito do Estado, dadas as suas notórias deficiências na prestação de bons serviços. Outra parte está ligada à visão equivocada a respeito da chamada "indústria de multas". O desafio, no caso, é mostrar para a sociedade as vantagens de um sistema eficaz de fiscalização, no que tange principalmente à defesa da vida e à melhoria das condições de circulação para todos.

Isso só se consegue com programas permanentes de comunicação, aliados a um trabalho competente por parte dos que realizam a fiscalização de trânsito. (vi) educação para o trânsito: O Código de Trânsito Brasileiro (CTB) tem um capítulo exclusivo da educação para o trânsito, considerada um direito de todos e um dever prioritário dos órgãos e das entidades componentes do Sistema Nacional de Trânsito (SNT), sendo obrigatória a existência de uma coordenação de educação em cada um desses órgãos. Também são exigidas a obrigatoriedade da realização de campanhas educativas anuais e a adoção de currículo multidisciplinar com conteúdo programático de segurança no trânsito em todos os níveis de ensino, em especial no ensino do magistério.

É necessária uma visão multidisciplinar de todas essas questões para que se obtenha êxito nos modelos de mobilidade urbana entre o diálogo do Estado em conjunto com a sociedade em consonância com o setor privado fazer as melhorias necessárias e compartilhamento de uma gestão que possa criar, executar e fiscalizar o andamento das políticas públicas de trânsito para uma melhor qualidade de vida da sociedade.

\section{Referencias}

CAMPOS, Vânia. "Uma visão da mobilidade urbana sustentável." Revista dos Transportes Públicos 2 (2006): 99-106

DEINFRA. Plataforma Catarinense de Mobilidade Sustentável. Departamento Estadual de Infra-estrutura, Governo do Estado de Santa Catarina. 2008. Disponível em: http://www.deinfra.sc.gov.br/pcms/ Acesso em: 21 mai. 2016. 
Id on Line Revista Multidisciplinar e de Psicoloqia

Id on Line Revista Multidisciplinar e de Psicologia

EMPRESA PÚBLICA DE TRANSPORTE E CIRCULAÇÃO, MOVIMAN Porto Alegre. MOVIMAN e EUROPE AID Serviço de Cooperação. 2006. Disponível em: http://www.eptc.com.br/moviman/index.asp?cod_ctd=277\&tipo=conteudo\&item=Início.

Acesso em: 21 mai. 2016.

GUDMUNDSSON. H. Sustainable Transport and Performance Indicators. In: Hester, R.E \& Harrison, R.M (Eds). Issues in Enviromental Science and Technology, n 20, p. 35-63. 2004. Disponível em: http://forskningsbasen.deff.dk/ddf/rec.external?id=ruc20876. Acesso em: 21 maio 2016.

Ministério das Cidades (2006a). Curso Gestão Integrada da Mobilidade Urbana. Módulo II: Cidade, Cidadão e Mobilidade Urbana Sustentável. Ministério das Cidades, Programa Nacional de Capacitação das Cidades, Brasilia, Março, 2006.

Ministério das Cidades (2006b). Guia PlanMob para de Elaboração dos Planos Diretores de Transporte e Mobilidade. Secretaria Nacional de Transportes e Mobilidade Urbana, Brasília, maio, 2006.

OLIVEIRA, Marília; OLIVEIRA, Orlando; OLIVEIRA, Joaquim. Mobilidade Urbana e Sustentabilidade. V Encontro Nacional da Anppas. Florianópolis, 2010. Disponivel em: http://disciplinas.stoa.usp.br/pluginfile.php/197777/mod_resource/content/1/Mobilidade\%20 Urbana\%20e\%20Sustentabilidade.pdf. Acesso em 21 maio 2016.

Observatório das Metrópoles; Instituto Nacional de Ciência e Tecnologia: Evolução da frota de automóveis e motos no brasil 2001 - 2012. Relatório de 2013.

PLUME, Planning for Urban Mobility in Europe. Synthesis Report on Urban Sustainability and is Appraisal. 2003.

TOMTOM (EUA). TomTom Americas Traffic Index. 2013.

TRANSPLUS, Analysis of Land and Transport Indicators. 2002.

VASCONCELLOS, Eduardo; CARVALHO, Carlos Henrique; PEREIRA, Rafael. Transporte e mobilidade urbana. 2011.

WAISELFISZ, Julio. 2013. MAPA DA VIOLÊNCIA 2013. Ministério da Justiça. Acesso em: 30nov. 2013.

WAISMAN, Jaime. Avaliação dos Impactos do Tráfego na Mobilidade da População Infantil através da Análise de Correspondência Multipla. Revista Transportes, Rio de Janeiro, v. 8, 2000.

Como citar este artigo (Formato ABNT):

CRUZ FILHO, V.A.; NASCIMENTO, D.C. Mobilidade Urbana e redução de Acidentes de trânsito. Id on Line Revista Multidisciplinar e de Psicologia, Julho de 2016, vol.,10 n.30, Supl 2. p. 100-114. ISSN 1981-1179.

Recebido: 10/06/2016

Aceito: 18/06/2016 